\title{
EENVOUDIGE PHYSISCHE BEPALINGEN EN ENKELE TOEPASSINGEN DAARVAN OP WEST-INDISCHE GRONDEN
}

DOOR

DR. R. Hamilton

Reeds in 1911 verscheen van de Zweedse bodemkundige A. Atterberg de eerste publicatie over zijn, later vooral in OostIndië, door E. C. J. Mohr zo bekend geworden consistentieleer. Hij verdeelt hierbij de grond afhankelijk van haar watergehalte in verschillende consistentie-zones, welke van elkaar zijn gescheiden door z.g. consistentie-grenzen.

In Juni 1913 had Mohr deze methode persoonlijk bij Atterberg in Kalmar geleerd en paste haar daarna met slechts zeer geringe modificaties succesrijk op de tropische gronden van Indië toe. De voornaamste grenzen, die tegenwoordig nog direct bepaald worden, zijn de volgende vier:

$$
\begin{aligned}
& \text { vloeigrens } \\
& \text { kleefgrens } \\
& \text { uitrolgrens } \\
& \text { omslagpunt }
\end{aligned}
$$

Bij de vloeigrens bevat de grond net iets te veel water, zodat tengevolge van enkele stoten, twee afzonderlijke, elkaar rakende kluiten hun samenhang verliezen en ineen vloeien. Deze grens, die steeds aanwezig is, valt ongeveer samen met de maximale watercapaciteit van de grond.

De kleefgrens is dat punt, waarbij een natte grondbrei net niet meer aan een gladde metalen of porceleinen spatel (te vergelijken met de ploeg, spade of hak) kleeft en deze er dus practisch schoon blijvend door- en overheen bewogen kan worden. Zand, humusrijke of zeer kalkrijke gronden hebben geen kleefgrens.

Bij de uitrolgrens bevat de grond net iets te weinig water om zich nog tot staven of draden te laten uitrollen, doch gaat overlangs en dwars scheuren. Dit uitrollen geschiedt met de

$$
-321-
$$


vlakke hand op een geen vezels afgevend, doch wel water opnemend stevig stuk pakpapier. Een uitrolgrens is niet altijd aanwezig; zand, humusrijke of zeer kalkrijke gronden hebben er geen.

Het omslagpunt tenslotte, dat steeds te bepalen is, is die grens waarbij een natte grondmassa door waterverlies van kleur verandert. Ruw gesproken is deze grens wat hoger dan de hygroscopiciteit van de grond. Daar de hygroscopiciteit een maat is voor de fijnkorreligheid van het monster, kan het omslagpunt hiervoor dus eveneens als globale grootheid gebezigd worden.

Al deze grenzen worden bepaald door de gezeefde grond $(<2 \mathrm{~mm})$ in een stevig porceleinen schaaltje met water aan te lengen en met een spatel te bewerken tot het gewenste punt bereikt is. Dit vochtgehalte wordt dan door ruim drie uur drogen bij $105^{\circ} \mathrm{C}$ bepaald en in procenten van de droge fijnaarde uitgedrukt.

In het algemeen bevat de grond bij haar vloeigrens het meeste en bij haar omslagpunt het minste water. De watergehalten voor de kleef- en uitrolgrens liggen hier tussen in, waarbij de uitrolgrens steeds lager ligt dan de kleefgrens. Bij lichte gronden is de kleefgrens echter hoger dan de vloeigrens.

Al deze grenzen blijken sterk afhankelijk te zijn van de stof$(2-20 \mu)$ en kleifractie $(0-2 \mu)$ en lopen hier vrij regelmatig mee op. Dit geldt zowel voor tropische als voor Europese gronden; wel is de correlatie met de fractie $0-20 \mu$. beter dan met die van $0-2 \mu(1 \mu=0,001 \mathrm{~mm})$.

Van deze vier direct bepaalde waarden worden door onderlinge aftrekking nog vier andere cijfers afgeleid, die dus het vochttraject tussen die grenzen vormen, en aldus heten:

plasticiteit $=$ vloeigrens minus uitrolgrens

surplus(taaiheid) $=$ kleefgrens minus vloeigrens

bewerkbaarheid $=$ kleefgrens minus uitrolgrens

maximale watervoorraad $=$ vloeigrens minus omslagpunt.

De plasticiteit is een ruwe maat voor de klei-eigenschappen van de grond als: kneedbaarheid, vormbaarheid, smeerbaarheid of anders gezegd van haar ,,vetheid”. Bij de vloeigrens is de grond dun breiig en vloeibaar, bij de uitrolgrens echter hard en stijf. Het verschil hiertussen zegt dus iets over de plastische eigenschappen ervan.

Het surplus wordt door Atterberg ,,taaiheid" genoemd en kan een positieve of een negatieve waarde hebben. Lichte, dus niet taaie gronden hebben een positief surplus (kleefgrens $>$ vloei- 
grens), zware taaie gronden echter een negatief cijfer (kleefgrens < vloeigrens). Dit had reeds Atterberg geconstateerd en hij voerde daarom deze aftrekking aldus in.

Het verschil tussen kleefgrens en uitrolgrens heet bewerkbaarheid en is ook een globaal cijfer om dit uit te drukken. Bij de kleefgrens wordt grondbewerking zeer bemoeilijkt door het kleven van de grond aan de gereedschappen; bij de uitrolgrens is bewerking lastig, omdat de grond dan te hard en stijf is.

De maximale watervoorraad is de hoeveelheid water, die een plant ten hoogste uit die grond kan opnemen m.a.w. de maximale door planten opneembare watervoorraad. Aangezien de vloeigrens overeenkomt met de watercapaciteit en het omslagpunt met de hygroscopiciteit en dit laatste watergehalte niet meer voor planten opneembaar is, wordt deze voorraad benaderd door het verschil tussen vloeigrens en omslagpunt.

Behalve deze acht bovengenoemde waarnemingen verricht men nog twee andere bepalingen en wel de zwaartegraad en de krimp.

Onder de zwaartegraad van een grond verstaat men de kraswaarde volgens een tiendelige schaal. De daartoe bij haar vloeigrens in een ondiep koperen bakje gebrachte natte grondbrei laat men hiervoor na het volkomen vlak strijken ongeveer twee weken buiten zon en wind geleidelijk geheel ,,luchtdroog" worden. Daarna bekrast men met flinke druk trekkend en duwend met een stevig, potlooddikke en iets afgeronde glasstaaf het gladde oppervlak en vergelijkt dan de samenhang, diepte, glans en hoeveelheid meel van de gevormde vore met onderstaande tiendelige schaal.

\begin{tabular}{|c|c|c|c|}
\hline $\begin{array}{c}\text { Graad } \\
\text { van } \\
\text { zwaarte }\end{array}$ & Benaming & $\begin{array}{c}\text { Bij het wrijven met de } \\
\text { glasstaaf }\end{array}$ & $\begin{array}{c}\text { Bij het wrijven met } \\
\text { de vinger }\end{array}$ \\
\hline 1 & Grof zand & \multicolumn{2}{|c|}{ Valt uit elkaar en geeft grove korreltjes } \\
\hline 2 & Fijn zand & $,, \quad, \quad, \quad,, \quad$, & fijne $\quad$, \\
\hline 3 & Stof & $\begin{array}{lllll},, & , & , & ,\end{array}$ & een fijn poeder \\
\hline 4 & Stof-leem & $\begin{array}{l}\text { Zeer diepe vore met zeer } \\
\text { veel meel }\end{array}$ & Vrij veel meel \\
\hline 5 & Lichte leem & Diepe vore met veel meel & Tamelijk veel meel \\
\hline 6 & Middelzware leem & $\begin{array}{l}\text { Tamelijk diepe vore met } \\
\text { vrij veel meel }\end{array}$ & Weinig meel \\
\hline 7 & Zware leem & $\begin{array}{l}\text { Ondiepe vore met betrek- } \\
\text { kelijk weinig meel }\end{array}$ & Zeer weinig meel \\
\hline 8 & Lichte klei & $\begin{array}{l}\text { Ondiepe vore met zeer } \\
\text { weinig meel }\end{array}$ & Geen meel \\
\hline$\circ$ & Middelzware klei & Geen vore, vrij doffe streep & ", \\
\hline 10 & Zware klei & $\begin{array}{l}\text { Geen vore, sterk glanzen- } \\
\text { de streep }\end{array}$ & , \\
\hline
\end{tabular}


Bij dit proefje bepaalt men tevens de lineaire verkorting van de grond tengevolge van het indrogen en noemt dit, in procenten uitgedrukt cijfer, de krimp. Het is een maat voor de werking (scheuren) van de grond.

Ofschoon al de z.g.n. Atterbergse cijfers niet tot in eenheden nauwkeuig zijn, hebben zij hun bruikbaarheid toch wel duidelijk bewezen, zodat ze in Oost-Indië nog altijd bepaald worden. Deze methode, die ook geschikt is voor uitvoering in het veld, vormt een eenvoudig en vlug te verrichten physisch onderzoek van de grond met een, voor de practijk voldoende, nauwkeurigheid van ongeveer twee procent. Bij uitvoering blijkt de methode bovendien veel minder subjectief te zijn dan men a priori geneigd is aan te nemen.

Een bezwaar der methode is alleen, dat men haar niet uit een voorschrift kan leren, doch haar persoonlijk moet leren kennen bij iemand. Ook Mohr heeft haar in 1913 persoonlijk bij Atterberg moeten leren en heeft haar nadien weer zelf herhaaldelijk aan anderen moeten voordoen. Een groot voordeel hiervan is, dat de bepalingen overal nog op de oorspronkelijke wijze worden verricht en dus de cijfers onderling volkomen vergelijkbaar zijn. Bij het vergelijken van zulke cijfers bedenke men echter, dit steeds slechts met gelijksoortige gronden te doen, aangezien men anders tot verkeerde resultaten geraakt. Tot nog toe zijn met deze werkwijze in Oost-Indië de volgende waarden gevonden. (Nul betekent hier ,,geen".)

\begin{tabular}{lr|lc} 
vloeigrens & $12-175$ & plasticiteit & $0-53$ \\
kleefgrens & $0-217$ & surplus & +42 tot -42 \\
uitrolgrens & $0-136$ & bewerkbaarheid & $0-43$ \\
omslagpunt & $\frac{1}{2}-74$ & maximale watervoorraad $11-106$ \\
zwaartegraad & $1-10$ & & \\
krimp & $0-40$ &
\end{tabular}

Met behulp van deze cijfers kan men een voorlopige en globale indeling van zand-, leem- en kleigronden geven en wel als volgt:

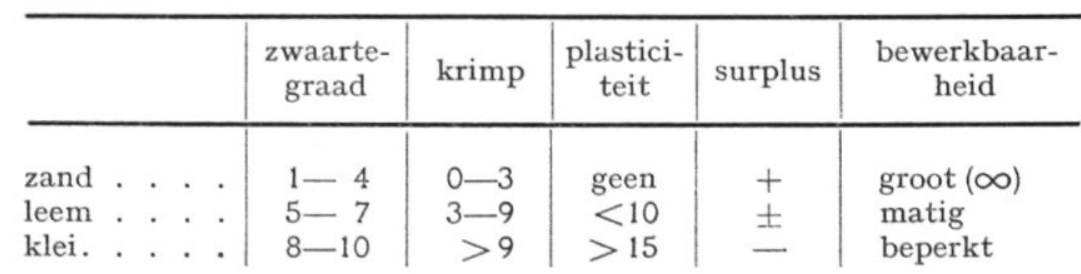


Bezien wij thans de met boven beschreven methoden verkregen cijfers der West-Indische (boven)gronden, dan kunnen we uit de bijgevoegde tabellen nog het volgende waarnemen.

TABel Ia. „Gewone” gronden der Ned. Antillen.

$\mathrm{A}=$ Aruba $\mathrm{B}=$ Bonaire $\mathrm{C}=$ Curaçao $\mathrm{E}=$ St. Eustatius

\begin{tabular}{|c|c|c|c|c|c|c|c|c|c|c|c|c|}
\hline Nr. & 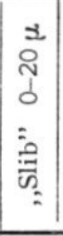 & 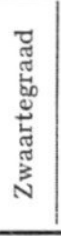 & 茎 & 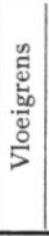 & 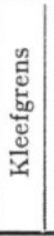 & 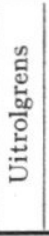 & $\begin{array}{l}\text { 品 } \\
\text { 品 } \\
\text { 号 } \\
\text { 号 }\end{array}$ & 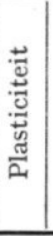 & 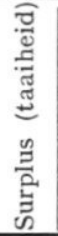 & 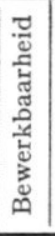 & 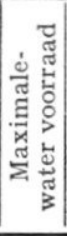 & Grondsoort \\
\hline $\mathrm{E}_{0}$ & 0,5 & 1 & 0 & 17 & & & 1 & & & & 16 & magnetiet zand \\
\hline $\mathrm{C}_{5}$ & 4,5 & 1 & 0 & 27 & & & 6 & & & & 21 & koraal zand \\
\hline $\mathrm{B}_{12}$ & 14,3 & $1-2$ & 0 & 26 & & & 6 & & & & 20 & bruin verwerings puin \\
\hline$A_{10}$ & 26,3 & $3-4$ & 2 & 28 & & 25 & 7 & 3 & & & 21 & kalkroodaarde \\
\hline $\mathrm{B}_{13}$ & 26,9 & $3-4$ & 2 & 27 & & 25 & 7 & 2 & & & 20 & diabaas roodaarde \\
\hline$B_{18}$ & 28,2 & $3-4$ & 3 & 27 & & 25 & 8 & 2 & & & 19 & ,, $\quad$, \\
\hline $\mathrm{E}_{4}$ & 29,2 & 4 & 2 & 30 & & 26 & 9 & 4 & & & 21 & grauwe andesiet grond \\
\hline$A_{9}$ & 30,7 & 4 & 2 & 31 & & 26 & 9 & 5 & & & 22 & grauwe kalk grond \\
\hline $\mathrm{E}_{1}$ & 37,0 & $5-6$ & 5 & 34 & & 24 & 8 & 10 & & & 26 & andesiet roodaarde \\
\hline $\mathrm{A}_{4}$ & 43,6 & 6 & 8 & 35 & 29 & $?$ & 9 & ? & -6 & $?$ & 26 & groen verwerings puin \\
\hline $\mathrm{B}_{8}$ & 46,2 & 7 & 8 & 35 & 29 & $?$ & 9 & ? & -6 & $?$ & & kalk roodaarde \\
\hline$B_{14}$ & 58,9 & 8 & 10 & 44 & 39 & 31 & 13 & 13 & -5 & 8 & 31 & 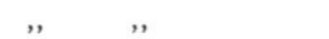 \\
\hline $\mathrm{B}_{15}$ & 60,4 & 7 & 9 & 42 & 38 & 30 & 13 & 12 & -4 & 8 & 29 & , , , \\
\hline $\mathrm{C}_{1}$ & 62,3 & 7 & 9 & 43 & 38 & 29 & 12 & 14 & -5 & 9 & 31 & diabaas roodaarde \\
\hline $\mathrm{C}_{8}$ & 79,4 & 9 & 14 & 43 & 39 & 30 & 13 & 13 & -4 & 9 & 30 & grauw salinja slik \\
\hline $\mathrm{B}_{9}$ & 80,4 & $9-10$ & 16 & 63 & 40 & 33 & 15 & 30 & -23 & 7 & 48 & ,, , , , \\
\hline
\end{tabular}

Tabel Ia omvat de ,,gewone” gronden der ,,aride” Nederlandse Antillen en laat duidelijk zien het regelmatig oplopen der cijfers met toenemend slibgehalte van $0-20 \mu$. Echte zanden staan dan ook boven aan en de zware, weinig voorkomende kleien onder in de reeks. De meeste monsters behoren echter tot de goed bewerkbare leemgronden. Dit verband was zo goed, dat hiermede soms zelfs een controle mogelijk bleek op de slibanalyse.

Geen dezer gronden bevat meer dan 7\% kalk, $1 \%$ chloor of $3,7 \%$ humus. Alleen $\mathrm{A}_{9}$ heeft $40 \%$ kalk, wat blijkbaar de bepalingen nog niet heeft gestoord.

Voor de slibanalyse wordt de grond 4 à 6 uur met verdunde ammonia geschud, doch niet ontdaan van haar humus noch van haar kalkgehalte. In verdunde ammonia wordt daarop door middel van de gewone pipetmethode de fractie 0-20

Helaas was niet van alle beschikbare grondmonsters voldoende materiaal meer aanwezig om de volledige cijferreeks bijeen te 
brengen. Van $\mathrm{A}_{4}$ en $\mathrm{B}_{8}$ kon daarom de uitrolgrens niet goed meer worden bepaald.

Met de toename van de slibfractie en dus het zwaarder worden der gronden kan men verwachten, dat de bewerkbaarheid afneemt. Deze tendens komt uit de cijfers van dit tabelletje echter niet geprononceerd naar voren. Men bedenke echter, dat een bijna gelijkblijvende cijferwaarde bij een toenemend slibgehalte in werkelijkheid echter toch reeds een (relatieve) daling betekent.

TABEL Ib. „Ongewone” gronden der Ned. Antillen. $\mathrm{A}=$ Aruba $\mathrm{B}=$ Bonaire $\mathrm{C}=$ Curaçao

\begin{tabular}{|c|c|c|c|c|c|c|c|c|c|c|c|c|}
\hline Nr. & 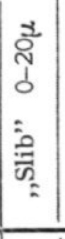 & 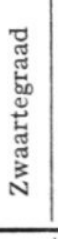 & 貼 & 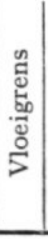 & 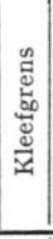 & 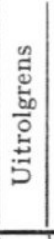 & 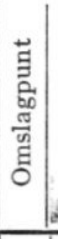 & 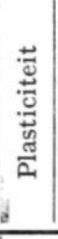 & 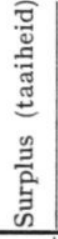 & 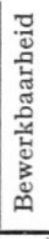 & 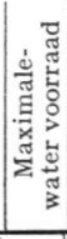 & Grondsoort \\
\hline $\mathrm{B}_{\mathrm{E}}$ & 14,1 & $2-3$ & 0 & 54 & & & 18 & & & & 36 & bruine grot ,"grond" \\
\hline$A_{A}$ & 27,0 & $3-4$ & 4 & 31 & 24 & 23 & 11 & 8 & -7 & 1 & 20 & roode , , , \\
\hline $\mathrm{B}_{16}$ & 15,5 & 4 & 0 & 38 & & & 11 & & & & 27 & witte kalk ,, \\
\hline $\mathrm{C}_{6}$ & 45,5 & 4 & 5 & 39 & & 31 & 12 & 8 & & & 27 & bruine kalk ,, \\
\hline$B_{17}$ & 41,9 & 1 & 0 & 26 & & 24 & 14 & 2 & & & 12 & witte meer ,, \\
\hline $\mathrm{B}_{10}$ & 64,0 & 4 & 0 & 25 & & 24 & 12 & 1 & & & 13 & grauwe meer ,, \\
\hline $\mathrm{B}_{7}$ & 39,4 & 3 & 5 & 52 & & 49 & 16 & 3 & & & 36 & kalkroodaarde \\
\hline$A_{8}$ & 50,6 & 3 & 6 & 49 & & 41 & 15 & 8 & & & 34 & , $\quad$, \\
\hline $\mathrm{C}_{4}$ & 59,2 & 3 & 7 & 50 & & 43 & 16 & 7 & & & 34 & , \\
\hline
\end{tabular}

In tabel Ib zijn alle ,ongewone" gronden bijeen gebracht, die dus ook geheel afwijkende cijfers tonen. Onder ,ongewoon" heeft men hier te verstaan gronden met zeer veel kalk, zout of humus, alsmede ,grotgronden".

De monsters $B_{E}$ en $A_{A}$ zijn twee van zulke grotafzettingen. $B_{E}$ is een bruin guanorijk ,"poeder" en $A_{A}$ een schelpenrijke rode ,, aarde". $\mathrm{B}_{16}$ en $\mathrm{C}_{6}$ zijn beide kalkrijke gronden met respectievelijk $87 \%$ en $52 \%$ kalk. $\mathrm{B}_{17}$ en $\mathrm{B}_{10}$ zijn, twee zeer zoutrijke monsters die $9,9 \%$ en $5,4 \%$ chloor bevatten. $\mathrm{B}_{7}, \mathrm{~A}_{8}$ en $\mathrm{C}_{4}$ zijn voor deze streken humusrijke kalkroodaarden; ze hebben resp. 4,8, 4,2 en $4,1 \%$ humus, bepaald volgens de methode van Istcherekow.

Uit deze cijfers blijkt, dat hoge gehalten aan kalk, zout of humus de Atterbergse bepalingen ernstig storen en tot op zekere hoogte nivellerend op de cijfers werken. Vooral bij de ",humusrijke" gronden is deze eigenschap sterk merkbaar.

In tabel II en III zijn vervolgens de gronden van de humidere 
streken opgenomen en wel van Suriname en Cuba. Dezelfde regelmatigheden als in tabel Ia zijn ook hier goed merkbaar.

TABEL II. Diverse Surinaamse gronden.

\begin{tabular}{|c|c|c|c|c|c|c|c|c|c|c|c|c|}
\hline Nr. & 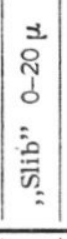 & 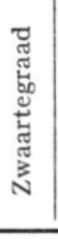 & 員 & 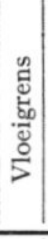 & 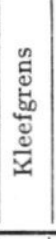 & 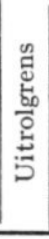 & 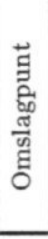 & 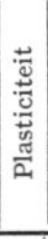 & 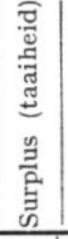 & 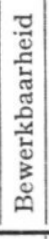 & 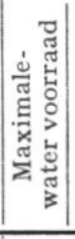 & Grondsoort \\
\hline 14 & $1, \mathrm{C}$ & 1 & 0 & 17 & & & 1 & & & & 16 & grof kwarts zand \\
\hline 13 & 1,0 & 2 & 0 & 22 & & & 2 & & & & 20 & fijn $\quad,, \quad$, \\
\hline VII & 2,4 & 1 & 0 & 21 & & & 1 & & & & 20 & grof $\quad,, \quad$, \\
\hline $\mathrm{I} a$ & 21,0 & 4 & 1 & 22 & & & 3 & & & & 19 & grauw savana zand \\
\hline II $a$ & 34,3 & 4 & 3 & 25 & & 16 & 6 & 8 & & & 19 & grauwe savana leem \\
\hline $\mathrm{X}$ & 64,9 & 6 & 6 & 33 & 32 & 23 & 8 & 10 & -1 & 9 & 25 & witte Pimba klei \\
\hline III $a$ & 73,5 & 6 & 8 & 41 & 36 & 26 & 10 & 15 & -5 & 10 & 31 & witte savana klei \\
\hline $233-3$ & 78,9 & $6-7$ & 9 & 48 & 38 & 29 & 10 & 19 & -10 & 9 & 38 & bruine kust klei \\
\hline $233-1$ & 81,8 & 9 & 9 & 60 & 42 & 33 & 15 & 27 & -18 & 9 & 45 & grauwe ,, ,, \\
\hline $2430-3$ & 88,9 & 10 & 12 & 64 & 46 & 38 & 14 & 27 & -18 & 8 & 50 & grauwe ,, \\
\hline
\end{tabular}

TABEL III. Cubaanse (suikerriet) gronden.

\begin{tabular}{|c|c|c|c|c|c|c|c|c|c|c|c|c|c|}
\hline Nr. & 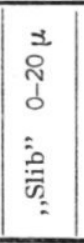 & 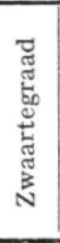 & 总 & 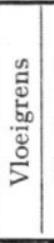 & 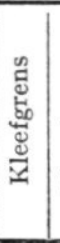 & 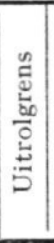 & 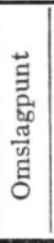 & 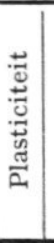 & 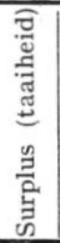 & 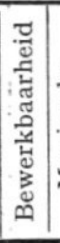 & 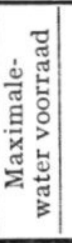 & & Grondsoort \\
\hline 385 & 39,6 & $3-4$ & 5 & 27 & 25 & 16 & 6 & 11 & -2 & 9 & 21 & kalk & roodaarde \\
\hline 89 & 44,0 & $6-7$ & 7 & 44 & 40 & 31 & 7 & 13 & -4 & 9 & 34 & , & \\
\hline 878 & 54,6 & 9 & 18 & 40 & 41 & 31 & 10 & 18 & -8 & 10 & 39 & $"$ & grauwaarde \\
\hline 879 & 57,1 & $6-7$ & 7 & 44 & 40 & 30 & 11 & 14 & -4 & 10 & 33 & ,", & roodaarde \\
\hline 892 & 72,3 & $9-10$ & 18 & 60 & 43 & 40 & 14 & 20 & -17 & 3 & 46 & ", & grauwaarde \\
\hline 891 & 75,1 & $9-10$ & 17 & 60 & 44 & 40 & 13 & 20 & -16 & 4 & 47 & ,. & 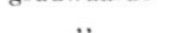 \\
\hline 890 & $(77,0)$ & 10 & 23 & 72 & 44 & 40 & 14 & 32 & -28 & 4 & 58 & ", & \\
\hline
\end{tabular}

Alle monsters uit deze tabellen zijn vrij van kalk en zout en bevatten ten hoogste 3,8\% humus. Storingen hierdoor komen dan ook niet voor. Het Cubaanse nummer 878 bevat echter 33\% kalk en toch heeft dit hoge gehalte blijkbaar nog geen invloed gehad.

Zoals te verwachten staan de bekend zware kalkgrauwaarden onderaan in tabel III en de in het algemeen lichtere rode gronden bovenaan. De zware Surinaamse kustkleiën (233-1 en 2430-3 zijn als gewoonlijk zeer slibrijk, niettemin vertonen zij slechts een 
matige krimp (scheuren) en blijken nog tamelijk bewerkbaar te zijn.

Humide gronden zijn gewoonlijk zwaarder dan die van aride streken. Men kan dit ook merken aan de vele hoge slibcijfers, zwaartegraden, krimpen en alle Atterbergse consistentiewaarden. Dit vindt zijn verklaring in de verwering, die in de humide tropen intensiever verloopt dan in de aride streken, waar het meer een mechanische vergruizing is dan een chemische afbraak. Wanneer hiertoe eens de kalkroodaarden van Aruba $\left(A_{10}\right)$ en Bonaire $\left(\mathrm{B}_{87}, \mathrm{~B}_{14}, \mathrm{~B}_{15}\right)$ met die van Cuba $(885,889,879)$ worden vergeleken, blijkt geen der Cubaanse monsters zo'n laag slib-, krimp- en plasticiteitscijfer te bezitten als dat van Aruba. Bovendien heeft $A_{10}$ geen kleefgrens. Hetzelfde kan waarschijnlijk ook voor de kalkgrauwaarden gezegd worden; hiervoor waren echter onvoldoende gegevens aanwezig.

Helaas is het cijfermateriaal veelal te gering om goede onderlinge vergelijkingen te maken of om betrouwbare grafieken samen te stellen. Ware het groter dan zou men zeer fraaie stippenbundels en zelfs -lijnen kunnen vormen uit het verband tussen alle Atterbergse waarden en de slibanalyse van overeenkomstige grondsoorten. Zulks is dan ook reeds voor Oost-Indische en Nederlandse gronden met succes geschied. Wanneer echter te weinig gegevens aanwezig zijn, krijgt men al gauw diffuse, weinig zeggende stippenzwermen.

Vergeleken met Nederlandse gronden zijn de Atterbergse waarden voor de tropen over het algemeen aanmerkelijk hoger. Ook dit vindt weer zijn verklaring in een volkomen verschillende verwering, die in de tropen veel sneller en intenser verloopt, zodat deze gronden veel meer colloiden en afslibbare delen bevatten. Duidelijk kan men dit merken bij het bepalen der omslagpunten. Waar de Nederlandse gronden om aan de lucht te drogen meestal slechts 1 à 2 kwartier nodig hebben kost dit voor vele tropengronden 1 à 2 uur.

Van het verweringsstadium zijn deze Atterbergse cijfers eveneens sterk afhankelijk. In 1915 heeft Mohr dit reeds aangetoond. Voor twee Zuid-Sumatraanse profielen op graniet en basalt vond schrijver dezes geheel hetzelfde en evenzo voor grauwe tabaksgronden op andesietas van Midden-Java. Goed ziet men dan, met het toenemen der verwering en dus ouder worden van de grond, het slibgehalte en alle Atterbergse waarden oplopen.

Ter illustratie moge hierbij het voorbeeldje uit Midden-Java 
volgen (tabel IV) en gewezen worden op de diabaasgronden $B_{13}$, $\mathrm{B}_{18}$ en $\mathrm{C}_{1}$.

TABEL IV. Asgronden van Midden Java.

\begin{tabular}{|c|c|c|c|c|c|c|c|c|c|c|c|c|}
\hline Nr. & 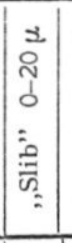 & 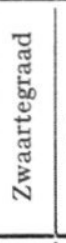 & 兽 & 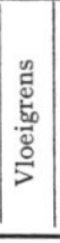 & 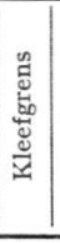 & 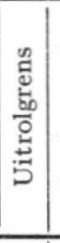 & 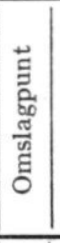 & 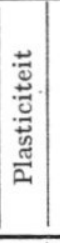 & 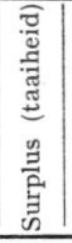 & 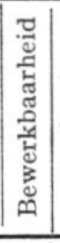 & 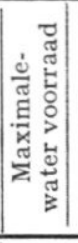 & Grondsoort \\
\hline $\begin{array}{l}\mathrm{K}_{1} \\
\mathrm{~K}_{2} \\
\mathrm{~K}_{4} \\
\mathrm{~K}_{5} \\
\mathrm{~K}_{6} \\
\mathrm{~K}_{7}\end{array}$ & $\begin{array}{r}2,1 \\
38,0 \\
44,8 \\
52,6 \\
53,3 \\
69,1\end{array}$ & $\begin{array}{r}1 \\
7 \\
7 \\
9 \\
8 \\
10\end{array}$ & $\begin{array}{r}0 \\
6 \\
5 \\
15 \\
15 \\
21\end{array}$ & $\begin{array}{r}(20) \\
31 \\
42 \\
42 \\
64\end{array}$ & $\left|\begin{array}{l}27 \\
31 \\
31 \\
41\end{array}\right|$ & $\begin{array}{l}19 \\
22 \\
23 \\
32\end{array}$ & \begin{tabular}{r|}
$(3)$ \\
7 \\
8 \\
8 \\
15
\end{tabular} & $\begin{array}{l}12 \\
20 \\
19 \\
32\end{array}$ & $\begin{array}{r}-4 \\
-11 \\
-11 \\
-23\end{array}$ & $\begin{array}{l}8 \\
9 \\
8 \\
9\end{array}$ & $\begin{array}{r}(17) \\
24 \\
34 \\
33 \\
49\end{array}$ & $\begin{array}{l}\text { recent grind } \\
\text { recente leem } \\
\text {,alluviale" leem } \\
\text { ", ", } \\
\text {,",tertiaire" ", klei }\end{array}$ \\
\hline
\end{tabular}

Resumerend kan men daarom zeggen, dat de methode van Atterberg een eenvoudig en snel uit te voeren physisch grondonderzoek vormt, dat in staat is het nodige te leren over de zwaarte, bewerking, verwering en indeling van de grond.

\section{LITERATUUR}

A. Atterberg. Die Plastizität der Tone (Int. Mitt. Bodenk. $I-10-1911$ ) —. Die Konsistenz und die Bindigkeit der Böden. (Int. Mitt. Bodenk. 2-149-1912)

. Die Plastizität und Bindigkeit liefernden Bestandteile der Tone. (Int. Mitt. Bodenk. 3-291-1913)

. Die Konsistenzlehre - Eine neue physikalische Lehre. (Koll Zeitschr. 20-1-1917)

G. BooBerg. De agrogeologisch belangrijkste eigenschappen der Java suikerrietgronden en het aanduiden van deze door een grond formule (Arch. suikerind. 36, II-1023-1931)

J. J. B. Deuss. Over de theegronden van Java en Sumatra. (Meded. Proefstat. Thee no. 89-1924)

E. C. J. Mohr. De methoden van Atterberg ter bepaling van consistentie cijfers en uitkomsten daarmede verkregen aan gronden van Java en Madoera. (Meded. Lab. Agrogeol. Grondonderzoek no. 1-1915)

- De methoden van grondonderzoek volgens Atterberg. (Versl. 3e verg. techn. pers. part. Proefst. Ambt. p. 69-1915) 